\section{On the offensive}

After decades of disappointment, and the investment of billions of dollars, is the 'war on cancer' about to gain real momentum?

\section{Alison Abbott sends a dispatch from the} front line.

W very few years a claim is made for a 'miracle drug' that will cure cancer. But time after time, compounds that have performed wonders in mice have failed miserably when faced with clinical reality.

Even cynics, however, have been taken aback by the performance of a drug called Gleevec, produced by the Swiss company Novartis, and approved by the US Food and Drug Administration (FDA) last year. It is not a cure-all, by any means. But against two particular types of cancer, Gleevec has achieved unprecedented results. For cancer researchers, the drug's remarkable success confirms that they are on the right track: understand which genes go wrong in cancer, design therapeutics to correct these defects, and the disease can be beaten.

"Gleevec is the proof of principle that the

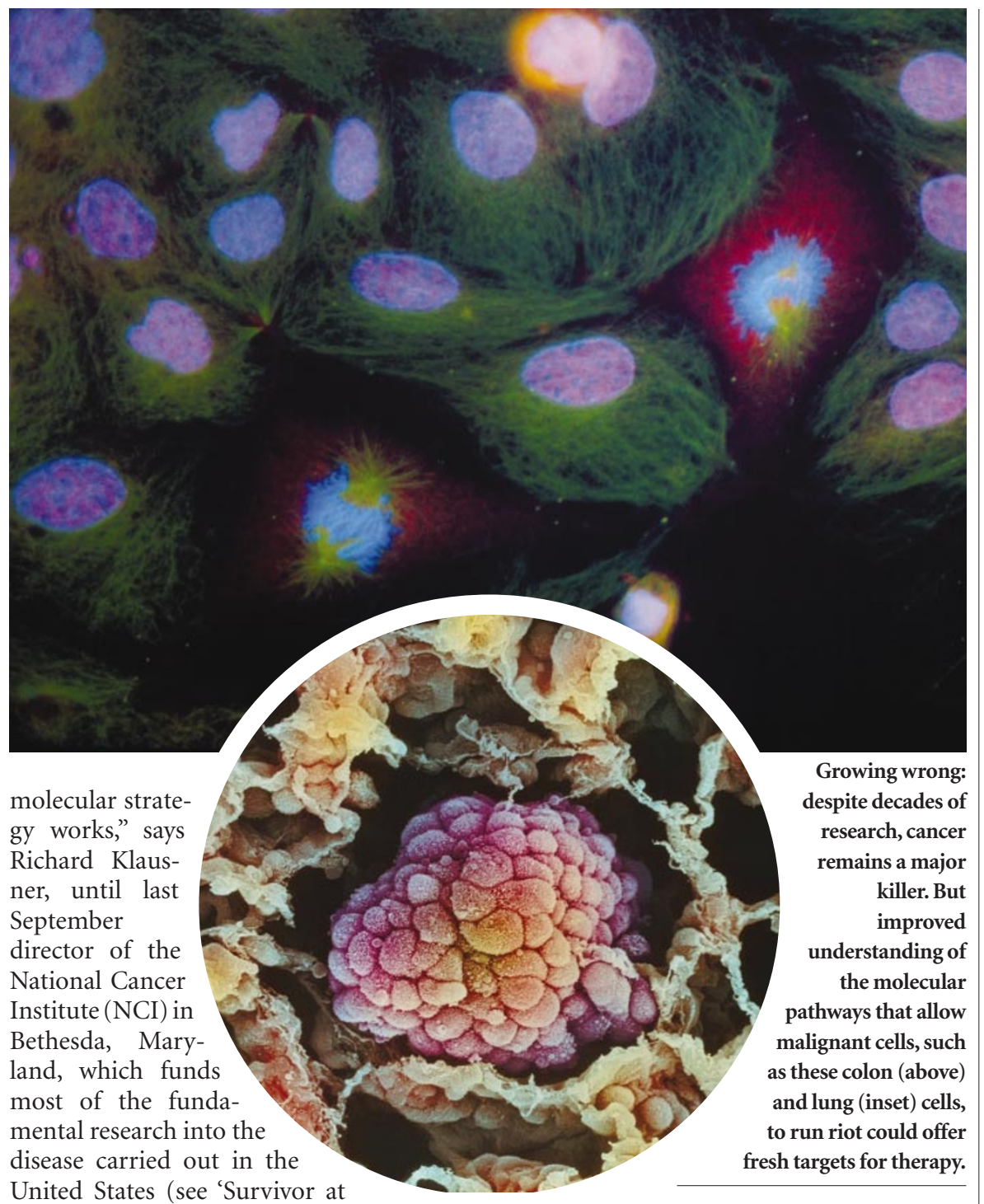
the helm', opposite).

That proof is long overdue. Conventional cancer chemotherapy, after decades of finetuning since it was introduced in the 1950s, has turned around the dismal outlook for

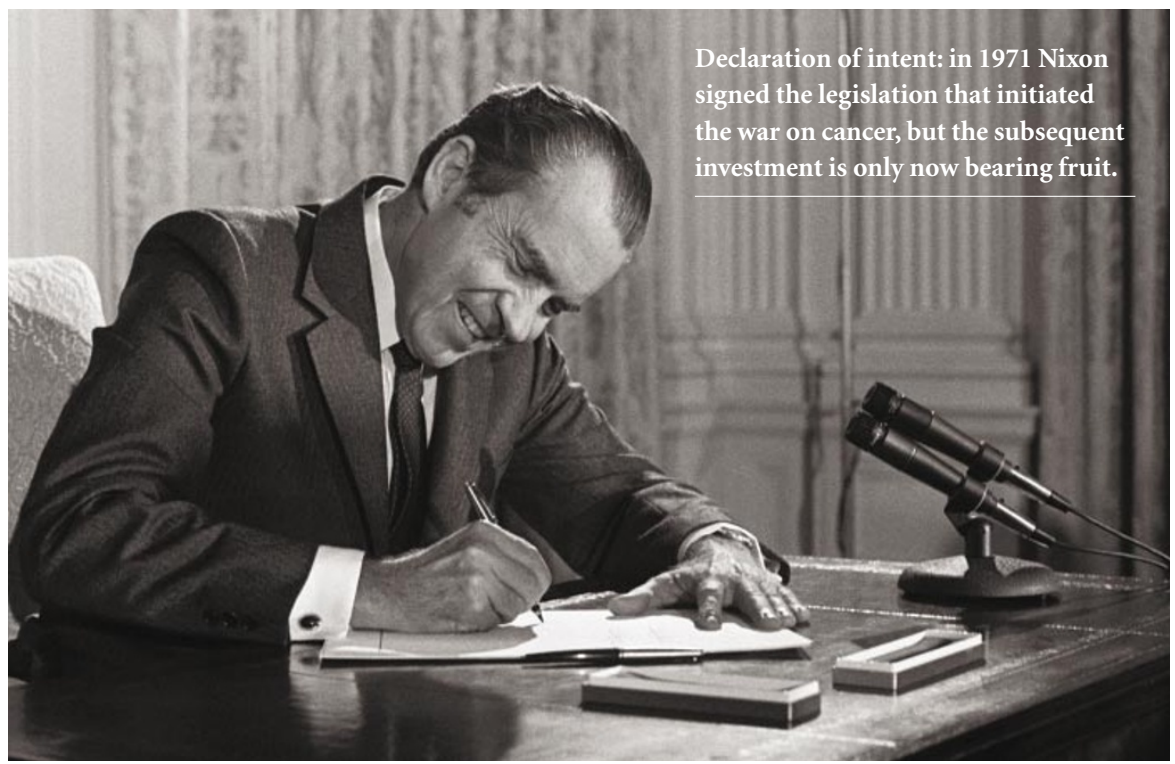

childhood leukaemias - up to $90 \%$ of cases are now curable. But against the big cancer killers - including breast, lung, prostate and colon cancers - there has been little progress (see figure, overleaf); sufferers usually experience only a brief period of remission. Even then the price is high, because the drugs are so toxic. Most current chemotherapy agents target dividing cells, for example by blocking the synthesis of new DNA required for cell division - and so hit many healthy organs as well as tumours. In particular, they damage bone marrow, where blood cells are produced.

With more than $\$ 46$ billion spent on cancer research by the US federal government alone since President Richard Nixon launched his 'war on cancer' in 1971, a minority of experts has even begun to suggest that cancer has become science's Vietnam. In a cutting essay in the February issue of Prospect magazine, for instance, cancer surgeon Michael Baum of University College London claimed that the fight against the disease was bogged down by "slavish adherence to outdated paradigms".

Until Gleevec, promises of kinder and 


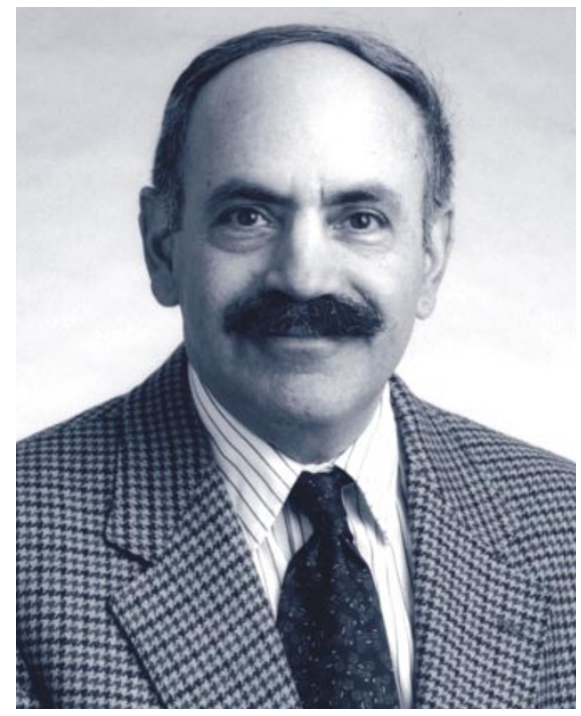

Robert Weinberg believes cancer's complex

more effective therapies had proved empty. leukaemia $(\mathrm{CML})$ respond to the drug, with the cancer being completely eliminated half of the time $e^{1,2}$. "It was extraordinary for clinicians to see such rapid and dramatic results," says Brian Druker, director of the Leukemia Center at the Oregon Health and Science University Cancer Institute in Portland, who stunning results, combined with a growing realization among cancer researchers that they have to start delivering the goods, have altered the outlook. The current catchphrase is 'translational research' - aiming to convert molecular insights into effective drugs.

Nixon launched his war on cancer as a successor to President John F. Kennedy's 1960 s dream of putting a man on the Moon. But according to some experts, the goal of defeating cancer by 1980 was always unrealistic. "We now understand that cancer is not a simple target that can be approached with high-tech hardware alone," says Klausner. Cancer, it is now realized, is a wily, shifting target - a battery of many different diseases, with a range of underlying causes.

In the vast majority of cases, cancer is an molecular interactions will give way to simplicity. But $95 \%$ of cases of chronic myelogenous conducted many of the clinical trials. These

acquired genetic disease. Cells accumulate a series of mutations that allow them to escape, with ever-greater freedom, the body's normal constraints on their proliferation. "But even mutations promoting unchecked growth are not actually enough to fire a fully fledged cancer," says Douglas Hanahan, a biochemist at the University of California, San Francisco.

In a recent review article ${ }^{3}$, Robert Weinberg of the Whitehead Institute for Biomedical Research in Cambridge, Massachusetts, together with Hanahan, described six 'hallmarks' of cancer - the acquired characteristics needed to turn a few wayward cells into an aggressive tumour.

\section{Marks of malignancy}

First, the cells must mutate so that they can dodge the cellular signals that suppress growth. Then they must acquire their own growth-signalling pathways, independent of external signals. Cells must also evade apoptosis, the system of programmed death under which abnormal cells trigger their own destruction. And they have to develop limitless potential to proliferate: normal cells can divide only about 70 times before their telomeres - the protective caps at the end of chromosomes - become so shortened that the chromosomes are damaged and the cell dies. But cancer cells exploit an enzyme called telomerase to rebuild their telomeres and so escape this constraint.

The other two cancer hallmarks apply only to solid tumours. Growing tumours must create their own networks of blood vessels to deliver the food and oxygen they need. This complex affair, known as angiogenesis, requires a multitude of special growth factors. Finally, the most dangerous tumours are those that have developed mechanisms to allow cells to detach from the main tumour and enter the bloodstream or the lymphatic system. From here they can reach distant tissues, where they grow into secondary tumours, or metastases. Nine out of ten cancer deaths result from metastases.

Very few cancers are caused by a single mutation. "There are so many things that need to go wrong, so it is not surprising that,

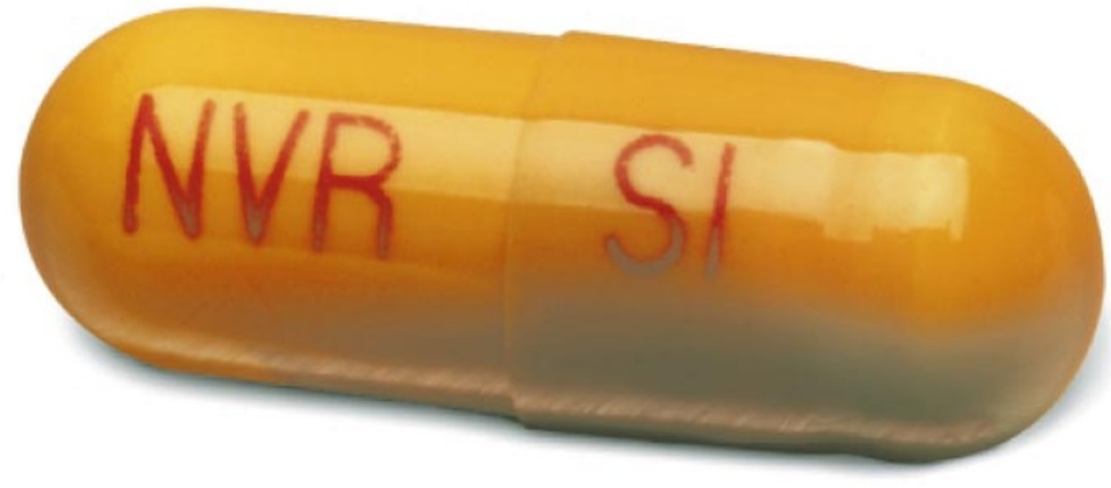

Pill power: Gleevec's success has boosted hopes for the molecular approach to cancer therapy. in a lifetime, cancer is actually rare," says Weinberg. This is why tumours caught early are usually easier to treat: mutations tend to accumulate as the cancer progresses. The fact that childhood leukaemias are caused by relatively few mutations also helps to explain why they have proved amenable to chemotherapy.

But the multiple changes needed to initiate and support a solid tumour offer a wide potential source of specific targets for scientists trying to develop anticancer drugs. First to be studied were the proteins produced by oncogenes - genes that, when activated,

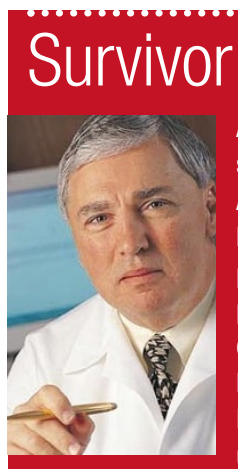

at the helm

After a quarter-century's service in the war on cancer, Andrew von Eschenbach finds himself in a central command post. A surgeon specializing in prostate cancer, the new director of the National Cancer Institute (NCI) in Bethesda, Maryland, declares a "sense of urgency" about the task in hand

Taking control:

Andrew von

Eschenbach. - he has fought a personal battle against prostate cancer and melanoma. "I know what it's like to wake up in the

middle of the night in a cold sweat and wonder if you're going to make it," von Eschenbach says.

That explains his commitment to the new mantra of 'translational research'. Von

Eschenbach pays tribute to his predecessor, Richard Klausner, who ensured that the NCI made major contributions to our understanding of cancer biology. Now, says von Eschenbach, it is time to convert those advances into therapies. "I want to emphasize our applications of that knowledge so that patients' lives are saved, and patients' pain and suffering are relieved," he says.

Like Klausner, von Eschenbach is a strong believer in the molecular approach, and illustrates its potential with an example from his agency's research portfolio. Just a few weeks ago, he notes, $\mathrm{NCl}$ scientists revealed that they could diagnose early ovarian cancers by analysing the proteins present in women's blood samples ${ }^{16}$.

But in his new position, charting the future of cancer diagnosis and therapy must sometimes take second place to immediate crises. Von Eschenbach started his job on 22 January; within a month, the $\mathrm{NCI}$ had to comment on a public row over the value of breast-cancer screening (see Nature 415, 567; 2002). "While I was still trying to figure out where the restroom was, the mammography controversy landed on my desk," he says.

Von Eschenbach spent most of his career working in the clinic at the University of Texas M. D. Anderson Cancer Center in Houston. And he still intends to spend half a day each week seeing prostate cancer patients. "I want to be able to sit across the bed from a patient and understand the reality of cancer," he says. Erika Check, Washington 


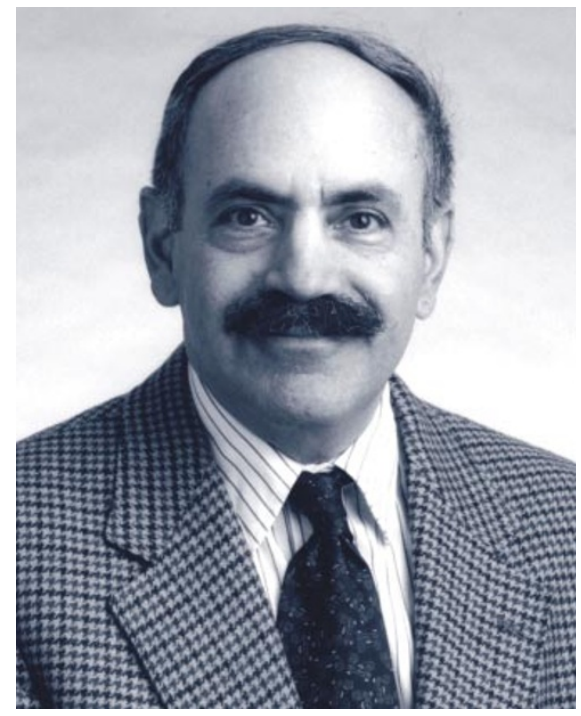

Robert Weinberg believes cancer's complex

more effective therapies had proved empty. leukaemia $(\mathrm{CML})$ respond to the drug, with the cancer being completely eliminated half of the time $e^{1,2}$. "It was extraordinary for clinicians to see such rapid and dramatic results," says Brian Druker, director of the Leukemia Center at the Oregon Health and Science University Cancer Institute in Portland, who stunning results, combined with a growing realization among cancer researchers that they have to start delivering the goods, have altered the outlook. The current catchphrase is 'translational research' - aiming to convert molecular insights into effective drugs.

Nixon launched his war on cancer as a successor to President John F. Kennedy's 1960 s dream of putting a man on the Moon. But according to some experts, the goal of defeating cancer by 1980 was always unrealistic. "We now understand that cancer is not a simple target that can be approached with high-tech hardware alone," says Klausner. Cancer, it is now realized, is a wily, shifting target - a battery of many different diseases, with a range of underlying causes.

In the vast majority of cases, cancer is an molecular interactions will give way to simplicity. But $95 \%$ of cases of chronic myelogenous conducted many of the clinical trials. These

acquired genetic disease. Cells accumulate a series of mutations that allow them to escape, with ever-greater freedom, the body's normal constraints on their proliferation. "But even mutations promoting unchecked growth are not actually enough to fire a fully fledged cancer," says Douglas Hanahan, a biochemist at the University of California, San Francisco.

In a recent review article ${ }^{3}$, Robert Weinberg of the Whitehead Institute for Biomedical Research in Cambridge, Massachusetts, together with Hanahan, described six 'hallmarks' of cancer - the acquired characteristics needed to turn a few wayward cells into an aggressive tumour.

\section{Marks of malignancy}

First, the cells must mutate so that they can dodge the cellular signals that suppress growth. Then they must acquire their own growth-signalling pathways, independent of external signals. Cells must also evade apoptosis, the system of programmed death under which abnormal cells trigger their own destruction. And they have to develop limitless potential to proliferate: normal cells can divide only about 70 times before their telomeres - the protective caps at the end of chromosomes - become so shortened that the chromosomes are damaged and the cell dies. But cancer cells exploit an enzyme called telomerase to rebuild their telomeres and so escape this constraint.

The other two cancer hallmarks apply only to solid tumours. Growing tumours must create their own networks of blood vessels to deliver the food and oxygen they need. This complex affair, known as angiogenesis, requires a multitude of special growth factors. Finally, the most dangerous tumours are those that have developed mechanisms to allow cells to detach from the main tumour and enter the bloodstream or the lymphatic system. From here they can reach distant tissues, where they grow into secondary tumours, or metastases. Nine out of ten cancer deaths result from metastases.

Very few cancers are caused by a single mutation. "There are so many things that need to go wrong, so it is not surprising that,

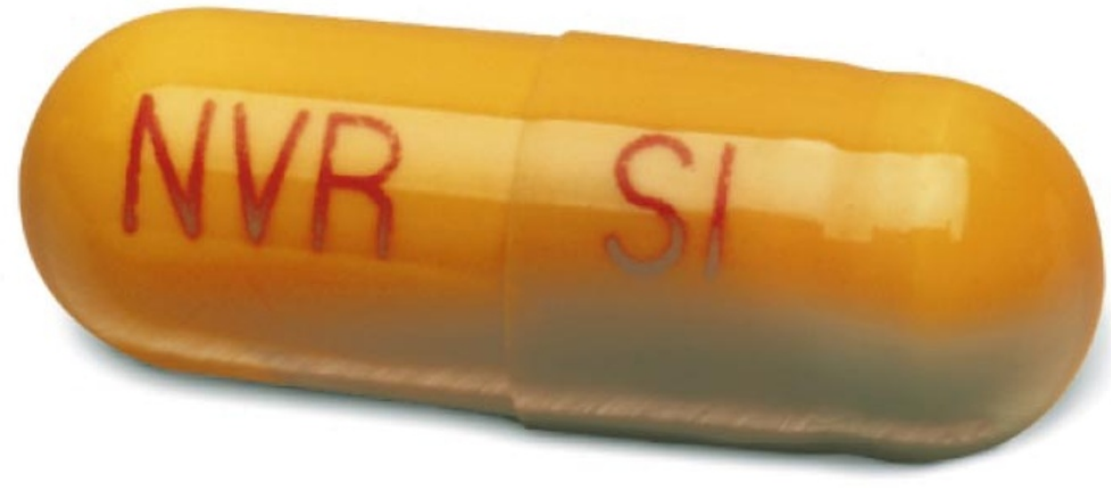

Pill power: Gleevec's success has boosted hopes for the molecular approach to cancer therapy. in a lifetime, cancer is actually rare," says Weinberg. This is why tumours caught early are usually easier to treat: mutations tend to accumulate as the cancer progresses. The fact that childhood leukaemias are caused by relatively few mutations also helps to explain why they have proved amenable to chemotherapy.

But the multiple changes needed to initiate and support a solid tumour offer a wide potential source of specific targets for scientists trying to develop anticancer drugs. First to be studied were the proteins produced by oncogenes - genes that, when activated,

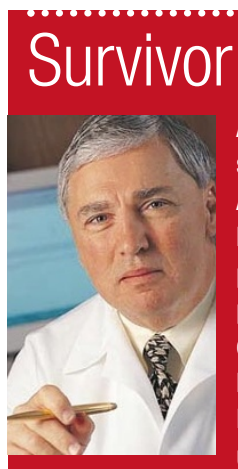

at the helm

After a quarter-century's service in the war on cancer, Andrew von Eschenbach finds himself in a central command post. A surgeon specializing in prostate cancer, the new director of the National Cancer Institute (NCI) in Bethesda, Maryland, declares a "sense of urgency" about the task in hand

Taking control:

Andrew von

Eschenbach. - he has fought a personal battle against prostate cancer and melanoma. "I know what it's like to wake up in the

middle of the night in a cold sweat and wonder if you're going to make it," von Eschenbach says.

That explains his commitment to the new mantra of 'translational research'. Von

Eschenbach pays tribute to his predecessor, Richard Klausner, who ensured that the NCI made major contributions to our understanding of cancer biology. Now, says von Eschenbach, it is time to convert those advances into therapies. "I want to emphasize our applications of that knowledge so that patients' lives are saved, and patients' pain and suffering are relieved," he says.

Like Klausner, von Eschenbach is a strong believer in the molecular approach, and illustrates its potential with an example from his agency's research portfolio. Just a few weeks ago, he notes, $\mathrm{NCl}$ scientists revealed that they could diagnose early ovarian cancers by analysing the proteins present in women's blood samples ${ }^{16}$.

But in his new position, charting the future of cancer diagnosis and therapy must sometimes take second place to immediate crises. Von Eschenbach started his job on 22 January; within a month, the $\mathrm{NCI}$ had to comment on a public row over the value of breast-cancer screening (see Nature 415, 567; 2002). "While I was still trying to figure out where the restroom was, the mammography controversy landed on my desk," he says.

Von Eschenbach spent most of his career working in the clinic at the University of Texas M. D. Anderson Cancer Center in Houston. And he still intends to spend half a day each week seeing prostate cancer patients. "I want to be able to sit across the bed from a patient and understand the reality of cancer," he says. Erika Check, Washington 
promote cell growth and division. Many, such as ras, which in 1982 became the first human oncogene to be cloned ${ }^{4-6}$, do this by stimulating signalling pathways normally activated by growth factors such as epidermal growth factor (EGF). In about 30\% of human cancers, ras is mutated so that it is permanently switched on, providing a constant growth signal to the cell ${ }^{7}$.

Unfortunately, the discovery of ras did not translate into a major clinical advance. Inhibitors targeting the ras system were developed by several pharmaceutical companies, but the first generation did not perform well in clinical trials. "We were too excited," admits Mariano Barbacid, director of the Spanish National Cancer Center (see 'The real deal in Madrid', below), who led one of the three groups that independently cloned the gene. "Some people had thought we had opened the door to curing cancer.”

The proteins produced by tumour suppressor genes, meanwhile, normally prevent cancerous growth. If the genes are damaged or lost, cells are more likely to become cancerous. The $p 53$ and $R b$ tumour suppressors, for instance, are inactivated in most tumours ${ }^{8}$. But proteins themselves do not make good drugs - they are hard to administer, and tend to get broken down in the body - so scientists are now trying to block key proteins in the molecular signalling pathways given free rein when tumour suppressor genes are inactive.

Many genes associated with cancer interact with several signalling pathways. For example, $p 53$ promotes apoptosis and activates DNA repair — and probably also inhibits angiogenesis'. Many oncogenes encode enzymes called tyrosine kinases, which add a phosphate group to a protein in a molecular pathway as a means of propagating the signal. Again, this activity can operate in several different signalling pathways.

Initially, drug development lagged behind the explosion of studies of cancer genes and the pathways that they influence. "The flood of identified oncogenes was very

\section{The real deal in Madrid}

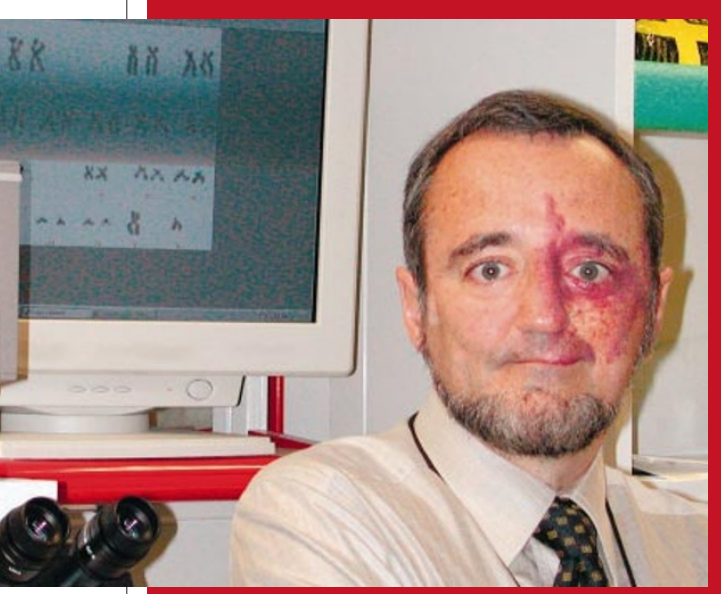

Appliance of science: Mariano Barbacid is aiming basic research at drug development.
Four years ago, Mariano Barbacid was made an offer he couldn't refuse: a chance to return to his native Spain to direct a new national cancer centre, with carte blanche to structure it however he saw fit.

In the early 1980s, while at the National Cancer Institute in Bethesda, Maryland, Barbacid led one of the teams that cloned the first human oncogene, ras. Later, as vice-president for oncology drug discovery at Bristol-Myers Squibb in Princeton, New Jersey, he absorbed the drug-industry culture. At the Spanish National Cancer Center, which moved into its new building in Madrid in February, Barbacid now aims to marry basic research with drug development.

The centre will conduct basic research into molecular and genetic oncology, but half of the 500 staff will work on applied projects in diagnostics and drug discovery. There will even be a medicinal chemistry programme to develop candidate drugs.

This is unusual for a cancer centre anywhere. It is virtually impossible for those in the United States to find funding for medicinal chemistry, says Frank McCormick, director of the Comprehensive Cancer Center at the University of California, San Francisco. "We form collaborations with pharmaceutical or biotech companies."

According to Barbacid's philosophy, this may often be just as well. "l've known some very clever scientists who say idiotic things about drug development," he says. But given Barbacid's experience in industry, he is optimistic of making progress — partly in-house, partly through links with drug companies. "We will concentrate on one or two targets," says Barbacid. "We don't expect to compete with big companies, but we may be lucky."

The centre's structure is designed to court good fortune. Barbacid has a staff member located in each of nine hospitals in the Madrid area to ensure good contacts with clinicians, and a supply of samples for the centre's tumour bank - more than 2,000 have already been collected. He is developing strong core facilities, including housing for 100,000 mice, plus facilities for microarray manufacture and the structural analysis of drug targets.

In practice, Barbacid is largely restricted to hiring Spanish researchers. "Spain cannot compete for postdocs internationally," he concedes. Fortunately, there are plenty of talented young scientists around, who have trained abroad and survived on short-term contracts since their return.

What Barbacid does not have is assured continuity of funds. The government currently covers half of the operational costs, but this has to be agreed annually — and Spanish politics can be fickle. The support of Spain's popular king has helped him so far, as has Barbacid's go-getting personal style. But that approach has made a few enemies, as well as friends $-\mathrm{so}$ the pressure is on to succeed. Alison Abbott, Madrid www.cnio.es/english interesting," says Barbacid. "But we got to a point where it was just another oncogene, another kinase, another pathway - and it was definitely time to put the knowledge in the service of the patient."

When drug companies moved in, they were particularly interested in cancer genes encoding tyrosine kinases, because the pharmaceutical industry has decades of experience in finding small molecules to block specific enzyme targets. Dozens of tyrosine kinase inhibitors are now being tested in the clinic, and Gleevec is the first to make it through.

\section{Toxic twist}

Gleevec was originally designed as a specific inhibitor for the platelet-derived growth factor receptor, which acts as a tyrosine kinase and has been implicated in some cancers. But the compound was later found to interact with proteins produced by two other oncogenes, $B C R-A B L$ and $c$-KIT. The former - a mutation caused by the fusion of sequences in the $A B L$ and $B C R$ genes is the trigger for $\mathrm{CML}^{10}$. It causes a recognizable chromosomal defect called the Philadelphia chromosome, in which chromosome 22 is shorter than normal.

Initially, pharmacologists were worried that Gleevec would have dangerous side effects. They were particularly concerned about its interaction with $c$-KIT, which, when functioning normally, is involved in regulating the immune system. "The fact is that Gleevec should have been toxic," says Barbacid, "but it wasn't." No one understands exactly how, but the immune system seems to be able to switch on other pathways to compensate for the blocking of the tyrosine kinase encoded by $c$-KIT.

Since its approval by the FDA in May 2001, positive clinical results ${ }^{1,2}$ have led to Gleevec's licence being extended in February this year to a rare stomach cancer, gastrointestinal stromal tumour (GIST) - a disease that is caused by the mutation of $c$-KIT (ref. 11).

Because they are caused by single mutations, CML and GIST are 'easy' diseases. But tyrosine kinase inhibitors are also being tested in messier situations - in cancers where many mutations have accrued. Even Gleevec does not perform quite so well in these circumstances. In a later and frequently fatal stage of CML called blast crisis, where many mutations have appeared, only around twothirds of patients respond to the treatment ${ }^{1}$. Resistance to the drug also develops quite quickly as $B C R-A B L$ mutated its way free of Gleevec's effects, or was overexpressed.

But at least one other tyrosine kinase inhibitor has performed well in early clinical trials against a notoriously difficult cancer. AstraZeneca's Iressa, directed against the tyrosine kinase activity of the EGF receptor, has excited oncologists by prompting a $10 \%$ response rate in patients with non-small-cell 
lung cancer who had failed to respond to other therapy. Although this might sound like a low response, the outlook for these patients is usually extremely bleak. "This is miracle-like," says Charles Sawyers of the Jonsson Comprehensive Cancer Center at the University of California, Los Angeles, who ran some of the Gleevec trials.

\section{Road blocks}

Other classes of drug have so far not performed as well, although efforts are continuing. A few years back, for instance, inhibiting angiogenesis by blocking the action of proteins such as vascular endothelial growth factor was thought to hold great promise. One front-page story in The New York Times, published in May 1998, infamously touted angiogenesis inhibitors as the longsought cancer 'cure'. But clinical trials of the drugs have so far disappointed - cancer cells seem to find it easy to get around the blockage of one angiogenic pathway.

There is also less excitement now about the potential for telomerase inhibitors, mostly because of concerns about their toxicity to stem cells in bone marrow, which also require the enzyme. And attempts to disrupt metastasis - using drugs called matrix metalloproteinase inhibitors to block an enzyme used by cells to chew their way out of the extracellular matrix that usually keeps them in place have so far disappointed in the clinic ${ }^{12}$.

Given previous experience, are researchers getting too excited about Gleevec? No, argue enthusiasts for the molecular approach. First, Gleevec is performing well where it matters in the clinic. Second, no one is pinning their hopes on one drug alone. Gleevec is merely the proof of principle that you can block a pathway that cancer cells depend on. In most cancers, it may be necessary to block pathways at several points, or even to target several
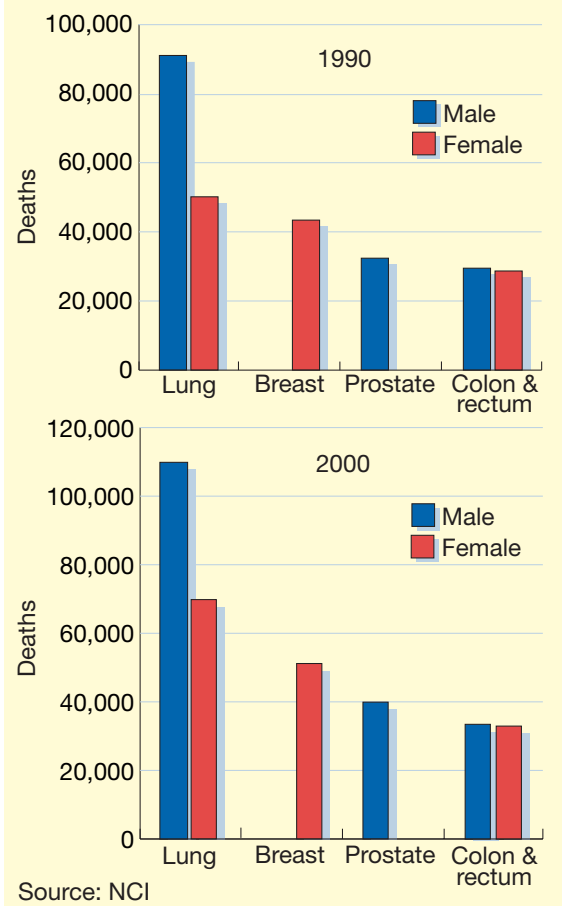

Slow progress: US mortality rates for the major cancer killers have changed little in 10 years.

pathways. So, repeating the success of Gleevec in other cancers may require cocktails of drugs - perhaps including some of those, such as the angiogenesis inhibitors, that have performed poorly in isolation.

"It is naive to think that in solid tumours we will get dramatic results by targeting one gene," says José Baselga, a clinical pharmacologist at the Vall d'Hebron University Hospital in Barcelona, who is organizing 58 clinical trials of tyrosine kinase inhibitors. "There will be many mutations, and so in future we can reckon on using combinations of drugs to hit many targets."
"This is what happened with AIDS treatments," agrees Edward Sausville, associate director of the NCI's developmental therapeutics programme. "Individual drugs did little on their own — but they worked very powerfully when they were put together.'

Specific drug combinations will probably need to be tailored to particular tumour types - which is why efforts to profile individual tumours to find out what, exactly, has gone wrong at the molecular level form an important new front in the war on cancer. "The first step is to understand the molecular profiles of cancers - then we'll need to identify targets," says Robert Strausberg, head of the Cancer Genome Anatomy Project at the NCI.

\section{Biological bull's-eyes}

In the past few years, huge investments have been made in new genomic technologies to do just this. Strausberg's project is the largest of many attempts to build up databases storing information on gene and protein expression, gene mutation and silencing, and clinical information such as the rate of disease progression and response to drugs. According to Sausville, these projects will lead to the recognition that types of cancer currently viewed by pathologists as identical are in fact distinct molecular diseases. "The most important thing we will learn is how to classify cancers better," he says.

Two recent papers, using DNA microarrays to look at gene expression in a lymphnode cancer called diffuse large B-cell lymphoma ${ }^{13}$ and in breast cancer $^{14}$ have illustrated the point: within each disease, cancers can be grouped into subsets with distinctive gene-expression profiles that correlate with how fast the disease progresses. Sawyers also suspects that the $10 \%$ response to Iressa seen in the lung cancer trials indicates that the tumours that responded had a
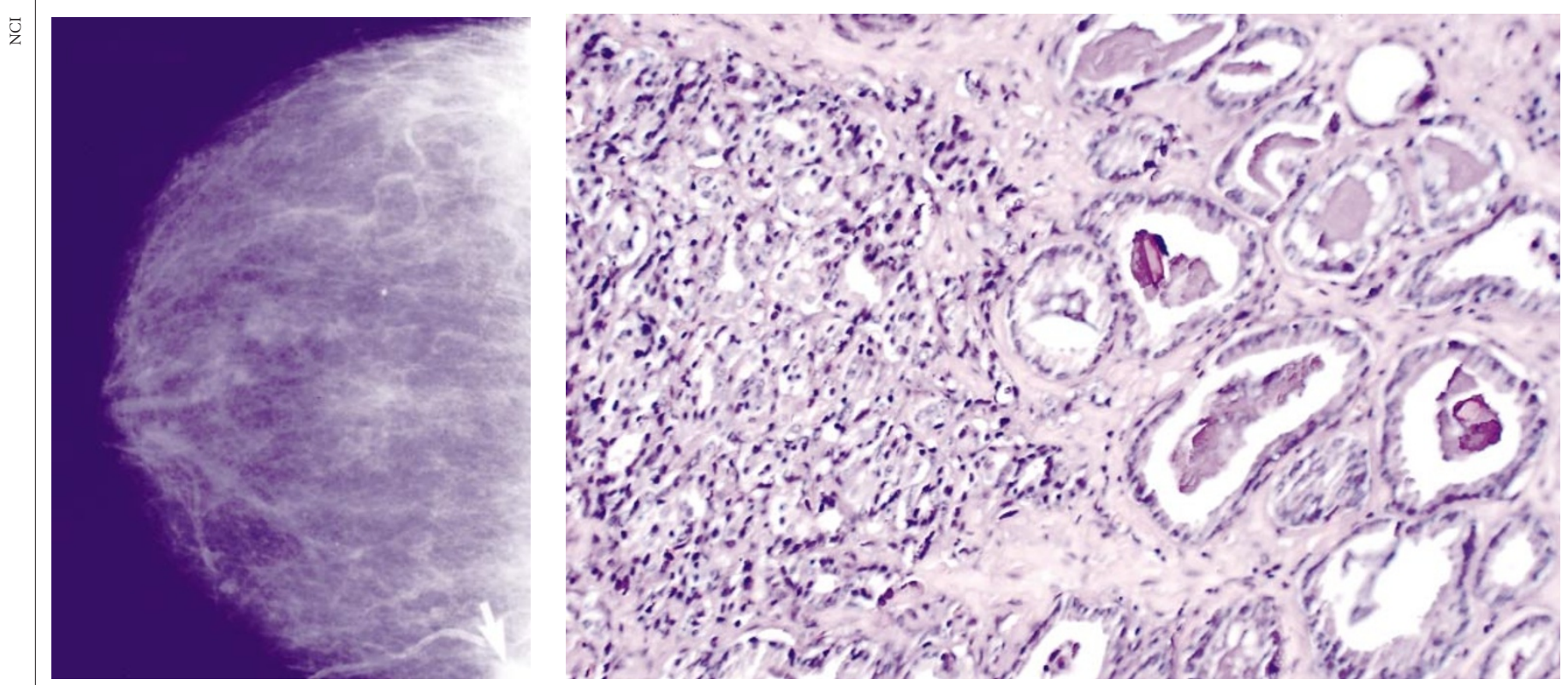

Fresh ammunition: could drugs targeted at specific molecular pathways provide a weapon against the 'big' killers such as breast (left) and prostate cancer? 
distinct molecular profile. "My hunch is that the EGF signalling pathway is the driving force in $10 \%$ of lung cancers, and the other $90 \%$ were different diseases," he says.

Molecular profiling should also allow scientists to identify markers for early diagnosis of cancer - proteins that could be measured in blood, faeces, urine or even in shed skin. "Early diagnosis is very important because the cure rate is very high for early-stage disease and very low for late-stage disease," says Lee Hartwell, director of the Fred Hutchinson Cancer Research Center in Seattle, who last year shared the medicine Nobel for his work on the cell cycle of growth and division.

Bruce Ponder, head of the University of Cambridge's Department of Oncology, and co-director of a new cancer centre being established at the university by the Medical Research Council and the charity Cancer Research UK (see 'Two into one', below), hopes to find molecular indicators of whether new drugs are working in clinical trials. "At the moment, tumour shrinkage is used as an endpoint and this is not only crude, but also delayed," he says.

Molecular profiling might also help clinicians to use currently available drugs more efficiently. "By comparing accumulating data on molecular profiles with outcomes of clinical treatment, we'll be able to identify, for example, which patients will not benefit from chemotherapy after surgery and spare them from useless, and very unpleasant, treatment," says Ponder.

\section{Informed choice}

In parallel with gathering data on tumours, some scientists are profiling cell lines used to study cancer in the lab. John Weinstein, a molecular pharmacologist at the NCI, is analysing gene and protein expression in the NCI's 60 standard cancer cell lines. Over the years, these cells have been used to test

\section{Two into one}

In Britain, the government plays second fiddle to the charitable sector in defining the agenda for cancer research. And in February, that became even more obvious with the merger of the two largest British cancer charities - the Cancer Research Campaign (CRC) and the Imperial Cancer Research Fund (ICRF) - to form Cancer Research UK. Officials argue that the merged organization, which boasts an annual budget of about $£ 150$ million (US\$214 million) and supports some 3,000 researchers, is better placed to meet the challenges of converting basic biological insights into effective new therapies. The ICRF, they point out, largely focused on fundamental research whereas the CRC carried out more clinical work.

"The merger has the potential to offer more streamlined drug discovery," says Linda Lashford, director of translational research at the new charity. "It should be much clearer to people who has the skills to move the process from one stage of the pipeline to the next." Access to equipment and resources should also improve, she predicts. For example, ICRF researchers will have easier access to a library of some 50,000 small molecules, used to screen against candidate drug targets, held at the CRC's laboratories in Sutton, near London.

Discussions about the merger were made public more than a year ago, but many details remain to be finalized - not least who will ultimately lead the new organization. ICRF chief Paul Nurse, who shared last year's medicine Nobel, and Gordon McVie, head of the CRC, have for now been made joint directorgenerals of the merged body. The post of interim chief executive has gone to an outsider, Andrew Miller, previously the vice-chancellor of Stirling University in Scotland and a former head of the European

Molecular Biology Laboratory's outstation in Grenoble, France. Miller's role is to steer the merger through its critical early months. He is combining the financial and administrative systems, setting up a senior

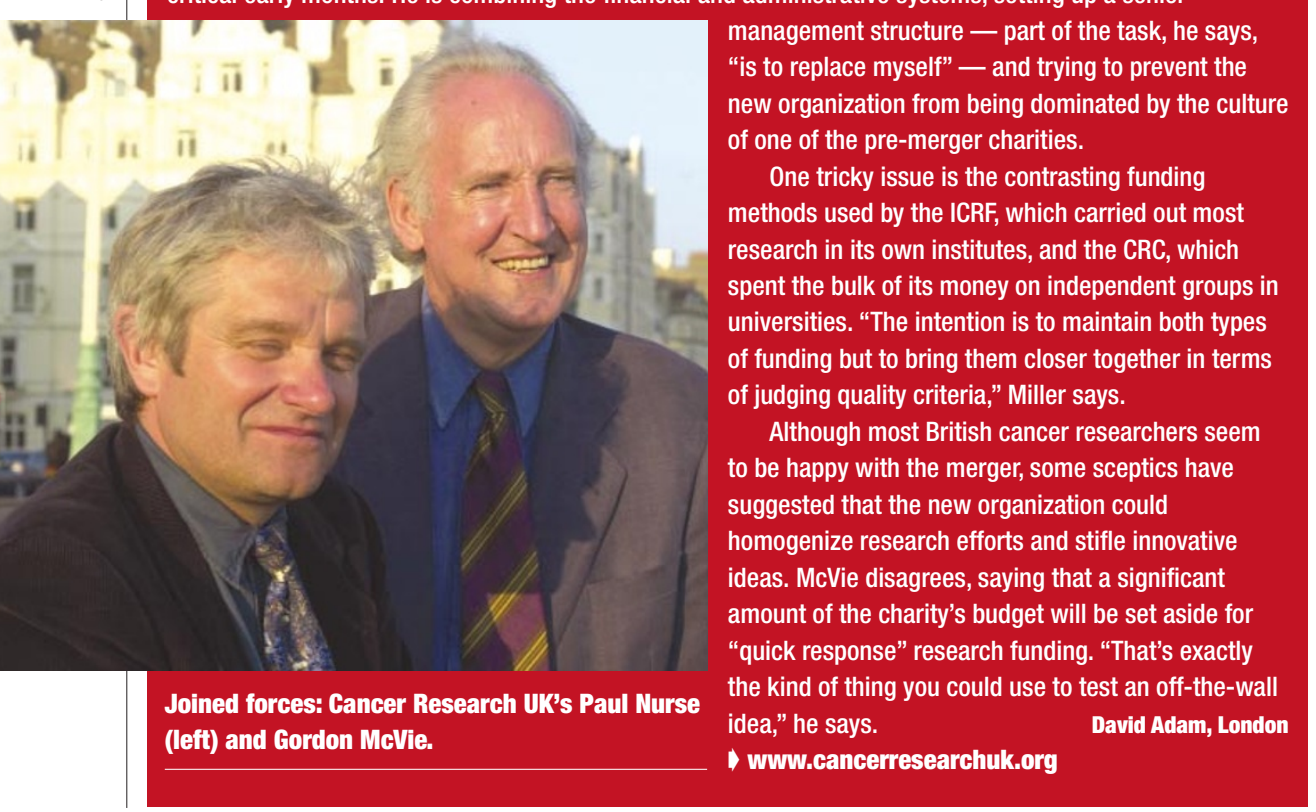
management structure - part of the task, he says, new organization from being dominated by the culture one of the pre-merger charities.

One tricky issue is the contrasting funding methods used by the ICRF, which carried out most research in its own institutes, and the CRC, which spent the bulk of its money on independent groups in universities. "The intention is to maintain both types of funding but to bring them closer together in terms judging quality criteria," Miller says. Although most British cancer researchers seen to be happy with the merger, some sceptics have suggested that the new organization could homogenize research efforts and stifle innovative ideas. McVie disagrees, saying that a significant amount of the charity's budget will be set aside for "quick response" research funding. "That's exactly idea," he says.

more than 70,000 different drugs. "There is a mine of pharmacological information there which we will correlate with the changes in gene and protein expression, to help us work out what types of drug will work best in a cancer with a particular expression profile," Weinstein says.

Already, Weinstein's research has turned up interesting pharmacological insights. For example, the enzyme L-asparaginase is used to treat acute lymphoblastic leukaemia (ALL) because it destroys the amino acid L-asparagine in the blood. This works because ALL cells are unable to make their own supply of the amino acid, so once their access to it in the blood is blocked, they die. Weinstein has found that ovarian cancer cell lines have similar patterns of gene expression to ALL cells, which suggests that they might also be sensitive to L-asparaginase ${ }^{15}$.

Molecular profiling will yield masses of data to add to our existing understanding of the signalling pathways that influence cancer. But from this complexity, leading researchers are convinced that simple insights will emerge. "Cancer biology and treatment... will become a science with a conceptual structure and logical coherence that rivals that of chemistry or physics," Hanahan and Weinberg argued in their 2000 review $^{3}$. They claimed that within two decades, cell biologists will have derived a complete integrated circuit of the cell's signalling pathways, allowing us to model how specific genetic perturbations cause cancer, and to predict how to correct the problem using drugs acting on key points in the circuit.

Other experts agree that marrying this 'systems biology' approach with weapons such as Gleevec holds great promise - not of defeating cancer within a few years, as Nixon once promised, but hopefully of seeing real progress in the ongoing war on cancer over the next decade or two. "History shows that therapy comes when you understand the system of the disease," says Bert Vogelstein, a leading cancer researcher at Johns Hopkins University in Baltimore, Maryland.

Alison Abbott is Nature's senior European correspondent. 1. Savage, D. G. \& Antman, K. H. N. Engl. J. Med. 346, 683-693 (2002)

2. Shawver, L. K., Slamon, D. \& Ullrich, A. Cancer Cell 1, 117-123 (2002).

3. Hanahan, D. \& Weinberg, R. A. Cell 100, 57-70 (2000)

4. Goldfarb, M. Shimizu, K., Perucho, M. \& Wigler, M. Nature 296, 404-409 (1982)

5. Parada, L. F., Tabin, C. J., Shih, C. \& Weinberg, R. A. Nature 297, 474-478 (1982)

6. Santos, E., Tronick, S. R., Aaronson, S. A., Pulciani, S. \&

Barbacid, M. Nature 298, 343-347 (1982).

. Bos, J. L. Cancer Res. 49, 4682-4689 (1989).

8. Sherr, C. J. Nature Rev. Mol. Cell Biol. 2, 731-737 (2001)

9. Dameron, K. M., Volpert, O. V., Tainsky, M. A. \& Bouck, N. Cold Spring Harb. Symp. Quant. Biol. 59, 483-489 (1994).

10. Shtivelman, E., Lifshitz, B., Gale, R. P. \& Canaani, E. Nature 315, 550-554 (1985)

11. Hirota, S. et al. Science 279, 577-580 (1998)

12. Coussens, L. M., Fingleton, B. \& Matrisian, L. M. Science 295, 2387-2392 (2002)

13. Alizadeh, A. A. et al. Nature 403, 503-511 (2000). 14. van't Veer, L. J. et al. Nature 415, 530-536 (2002). 15. Scherf, U. et al. Nature Genet. 24, 236-244 (2000). 16. Petricoin III, E. F. et al. Lancet 359, 572-577 (2002).

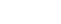

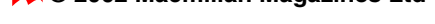

